\title{
Characterization of the geological and geotechnical conditions at the village of Monsanto
}

\author{
Isabel Fernandes ${ }^{1, *}$, Teresa Bodas Freitas $^{2}$, Ricardo Prazeres ${ }^{2}$, Carlos Neto de Carvalho $^{3}$, \\ João Calvão ${ }^{1}$ \\ ${ }^{1}$ IDL, Faculdade de Ciências da Universidade de Lisboa, Campo Grande, 4149-016 Lisboa, Portugal \\ ${ }^{2}$ CERIS, Instituto Superior Técnico, Universidade de Lisboa, Av. Rovisco Pais, Lisboa, Portugal \\ ${ }^{3}$ Município de Idanha-a-Nova; Geopark Naturtejo UNESCO, Castelo Branco, Portugal
}

\begin{abstract}
The stability of slopes and hillsides involving rock or soil masses depends crucially on the occurring geological and geotechnical conditions. The village of Monsanto, municipality of Idanha-a-Nova, is located on a granitic inselberg. The tourist interest of the village lies largely in the fusion of the granitic rock mass with the man-made constructions and in the aesthetics of several granitic boulders scattered throughout the village. In the present work the geological and geotechnical characterization of the rock mass has been carried out, namely by the field survey of the entire intervention area and by a set of laboratory tests on samples collected in the field (ultrasound propagation velocity and the uniaxial compression test). Based on this information, the shear strength of the discontinuities was estimated and a kinematic analysis was performed using the Dips 7.0 commercial software, with the objective of defining the predominant sets of joints and identifying the most probable failure mechanisms in each hillside.
\end{abstract}

\section{Introduction}

Monsanto is an historical Portuguese village built on a granitic rock mass inselberg, which landscape in dominated by large rock boulders and blocks (Figure 1).

In steep slopes, as those observed in Monsanto, the main types of mass movements are rockfalls, planar slides along discontinuities and toppling. Rockfall occurs for large size rocks blocks on steep slopes, with instability being associated to geologic, topographic or climatic factors [1]. According to [2] the susceptibility for landslides to occur increases with the slope angle but it is also influenced by the lithology. Usually loose materials are stable for angles lower than $27^{\circ}$, whilst slopes dipping more than $30^{\circ}$ do not allow the accumulation of rock boulders or loose materials. Slopes that dip more than $45^{\circ}$ are prone to rockfall and rock avalanches. Consequently, the slope angle is one of the parameters considered in the evaluation of the susceptibility of mass movements and associated risk, e.g. $[3,4]$.

\footnotetext{
* Corresponding author: mifernandes@fc.ul.pt
} 

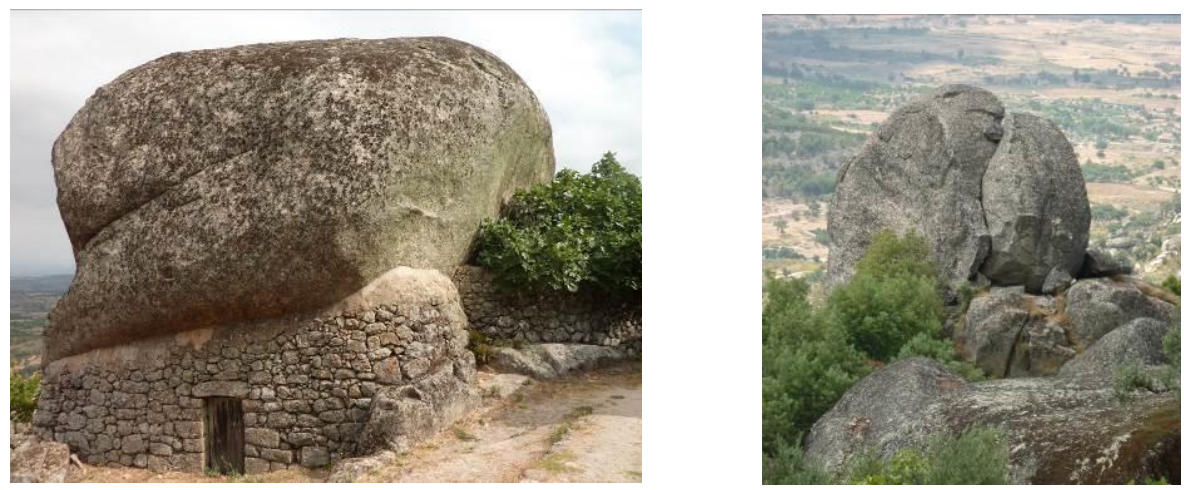

Fig. 1. Some rock blocks and boulders in Monsanto village. The boulders form the roofing and/or the walls of some houses and, outside the urban area, the rock mass forms blocky outcrops of moderately weathered to highly weathered granite.

The slope angle affects the type of movement and the trajectories of the rock block once the movement is initiated. In the study developed in [5], the authors state that there might be rockslides in slopes of less than $45^{\circ}$ but for slopes of $60-70^{\circ}$ there will be rockfalls and toppling, in particular when subvertical joints occur in the rock mass. Dorren [1] presents a review of the state of the art on the subject and concludes that the trajectories are directly dependent of slope angle: freefalling $\left(i>70^{\circ}\right)$, bouncing $\left(45 \leq i \leq 70^{\circ}\right)$ and rolling $\left(i<45^{\circ}\right)$ can occur. Besides the slope angle, the initiation of the movement and the way it develops are affected by the presence of obstacles and by the physical properties of the blocks, such as shape, lithology, weathering degree, position of the centre of mass, conditions of the support or occurrence of load from other blocks $[1,6,7]$.

The assessment of the probability of movement initiation by planar, wedge sliding or toppling can be performed by means of a kinematic analysis. On the other hand, the prediction of the trajectory of a block presents a high uncertainty as it depends on several factors. There are several academic and/or commercial software programs to predict block trajectories ([7, 8]; Rockfall, by Rocscience), which can be applied to assist in a risk analysis. The study of these phenomena requires a detailed knowledge of the geologicgeotechnical conditions including the mechanical and geometric parameters of the rock mass.

The present work is part of a wider project to carry out a hazard assessment of mass movements in Monsanto, Portugal. This paper presents the preliminary results of that project, namely the geologic-geotechnical characterization of the rock mass in the intervention area and the kinematic analysis for the identification and characterization of the mass movement triggering mechanisms. 


\section{Methodology}

The village of Monsanto is located on a rock mass outcrop that covers an area of $136 \mathrm{~km}^{2}$, consisting of two-mica medium to coarse-grained porphyroid granite. The rock outcrop has an elliptic configuration, with the long axis oriented $\mathrm{N} 35^{\circ} \mathrm{W}$ and is strongly weathered by hydrothermal action. The altitude of the hill varies between 400 to $745 \mathrm{~m}$ with the village being located approximately between elevation 620 and $670 \mathrm{~m}$. The inclination of the slopes and cliffs can reach up to $65^{\circ}$ but, due to the existence of several agricultural terraces, the area presents an average inclination of about $35^{\circ}$, which according to [3] is a moderate inclined slope. Figure 2 shows the hypsometric map and the slope map obtained by ArcGIS.
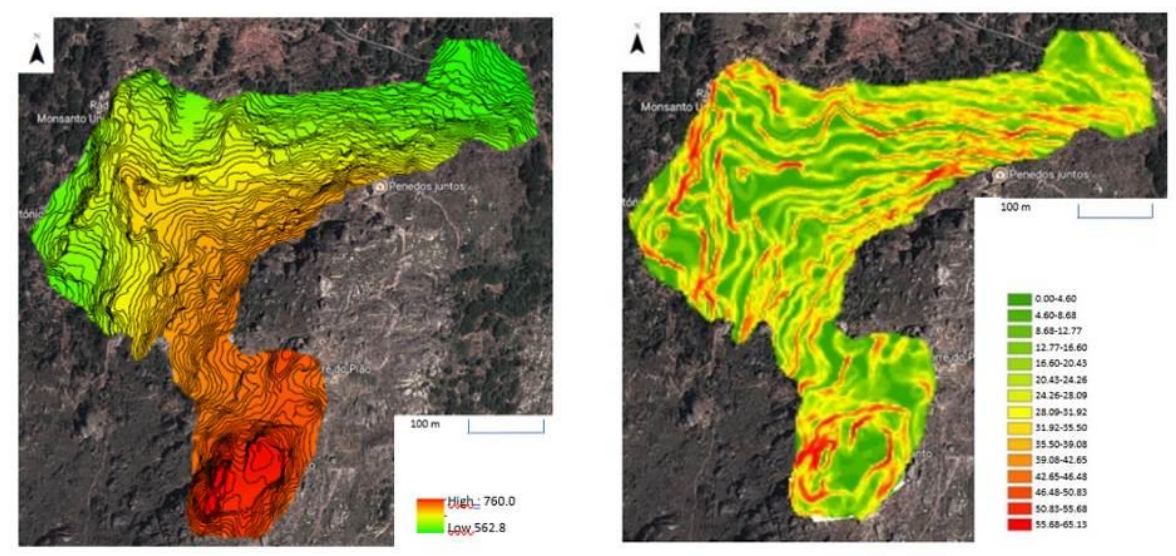

Fig. 2. Maps of the studied area: a) hypsometric map; b) slope map.

In order to characterize the rock mass, geologic-geotechnical survey of the rock mass was performed in a set of selected locations, named joint stations. The fieldwork focused on the locations were the rock mass outcropped, avoiding places were boulders had been subjected to ancient movements and therefore were no longer in-situ. The geologic-geotechnical survey followed the recommendations of the International Society of Rock Mechanics [9] and also the chart proposed in [10], namely in what concerns the degree of weathering (W) and fracturing $(\mathrm{F})$, and the characteristics of the joints: orientation, spacing, persistence, roughness, aperture, infilling. The roughness was estimated by comparison with reference profiles [11] for the Joint Roughness Coefficient (JRC). On each joint wall the Schmidt hammer was used to obtain the hardness [12] and to estimate the uniaxial compression strength, applying the correlation suggested in [13].

The most frequent dip/dip direction for each set of joints was obtained by plotting the pole of each joint on an equal-area net and defining contour diagrams with the software DIPs 7.0 of Rocscience. For each set of joints, histograms of the different physical properties were built to obtain the respective mean values. The joint stations were grouped into 5 sites, as a result of the similarities in the observations in some stations. Figure 3 shows a plan of the intervention area with indication of the 10 joint stations and 5 resulting sites. In addition to the fieldwork, laboratory tests were carried out to determine the ultrasound propagation velocity [14] and the uniaxial compressive strength [15]. These tests were performed on cylindrical cores $54 \mathrm{~mm}$ diameter and $142 \mathrm{~mm}$ in height, drilled from granitic blocks collected in a recent excavation. Based on all available information the shear strength of the joints was estimated using the methodology proposed in [11]. The kinematic analysis was carried out using the software Dips 7.0 (Rocscience) and considered 
the following types of mass movements: planar and wedge sliding, flexural and direct toppling.

\section{Results}

\subsection{Field Work}

Within the village, the rock outcrops are scarce, and they are frequently covered by buildings and/or partition masonry walls. In the area around the urban centre of the village there are numerous block chaos and blocks that rolled or fallen from higher elevation. These conditions have constrained the field characterization of the rock mass. Detailed field characterization was carried out at 10 survey locations across the intervention area, where the blocks were in situ and access was possible.

The rock blocks show a coating over the surface that might be whitish to dark in colour due to the presence of lichens, the colour varying with the exposure conditions. The blocks exhibit a yellowish coloration due to weathering, being classified as $\mathrm{W}_{3}$, sometimes $\mathrm{W}_{4}$ [9]. Locally they can present reddish coloration and evidence of oxidation. On the walls of the joints, in particular of sub-horizontal joints, it is common to observe quartz crystals standing out in relation to the rock matrix that has been eroded due to chemical and physical weathering. The blocks and boulders have large dimensions and show rounded edges and faces due to erosion. Frequently the contacts between blocks, or between the blocks and the supporting ground, are fully weathered, occurring as a sandy residual soil, and the contact area is very limited. In the NW area, the blocks are mainly prismatic with the larger dimension close to the vertical; conversely, in the East area the blocks are tabular and rest on sub-horizontal joints.

Due to the proximity between some of the joint stations and/or similarities in the occurring predominant joint sets, the 10 joint stations where grouped in 5 sites (Figure 3). Figures 4 and 5 show the attitude of the sets of discontinuities at the 5 sites.

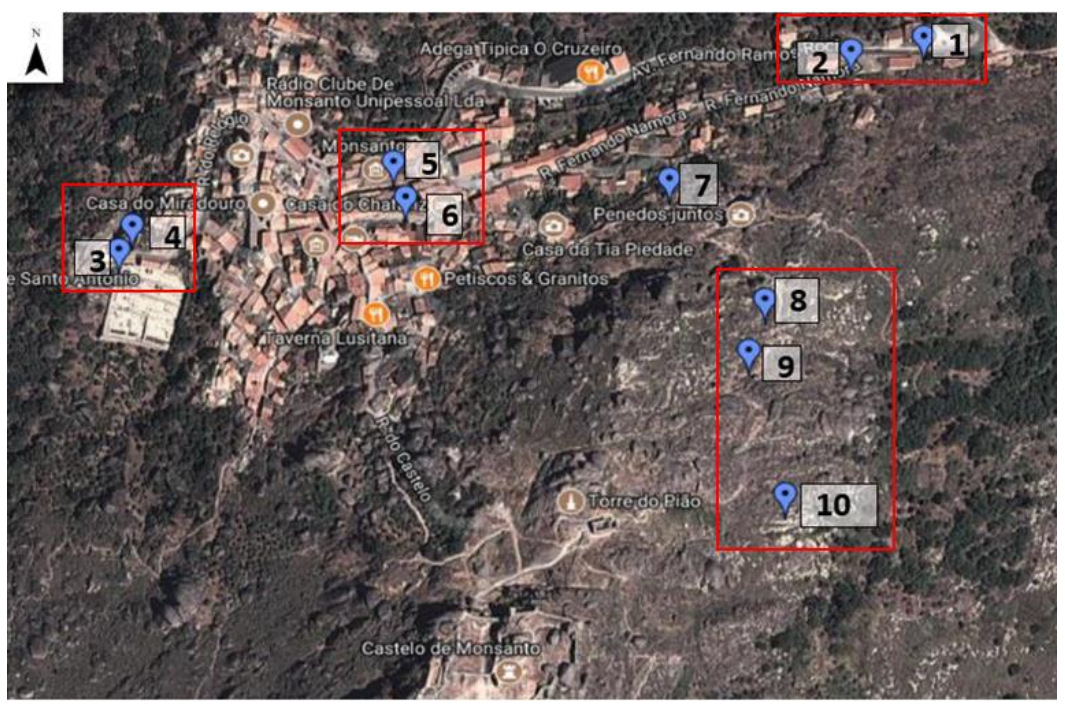

Fig. 3. Map of the intervention area with indication of survey locations for study of the joints sets. In general terms, it is found predominant subvertical joints with orientation NNE-SSW to NNW-SSE and ENE-WSW to ESE-WNW. The sub-horizontal joints show more scatter but dip predominantly to north. 


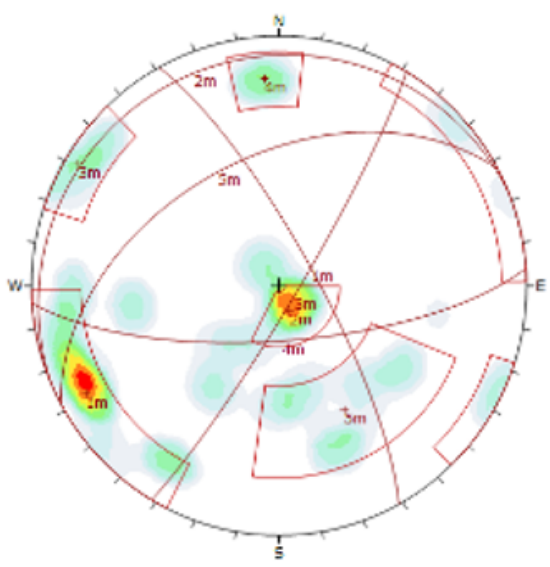

Site 1 (JS $1+$ JS 2) 76 poles
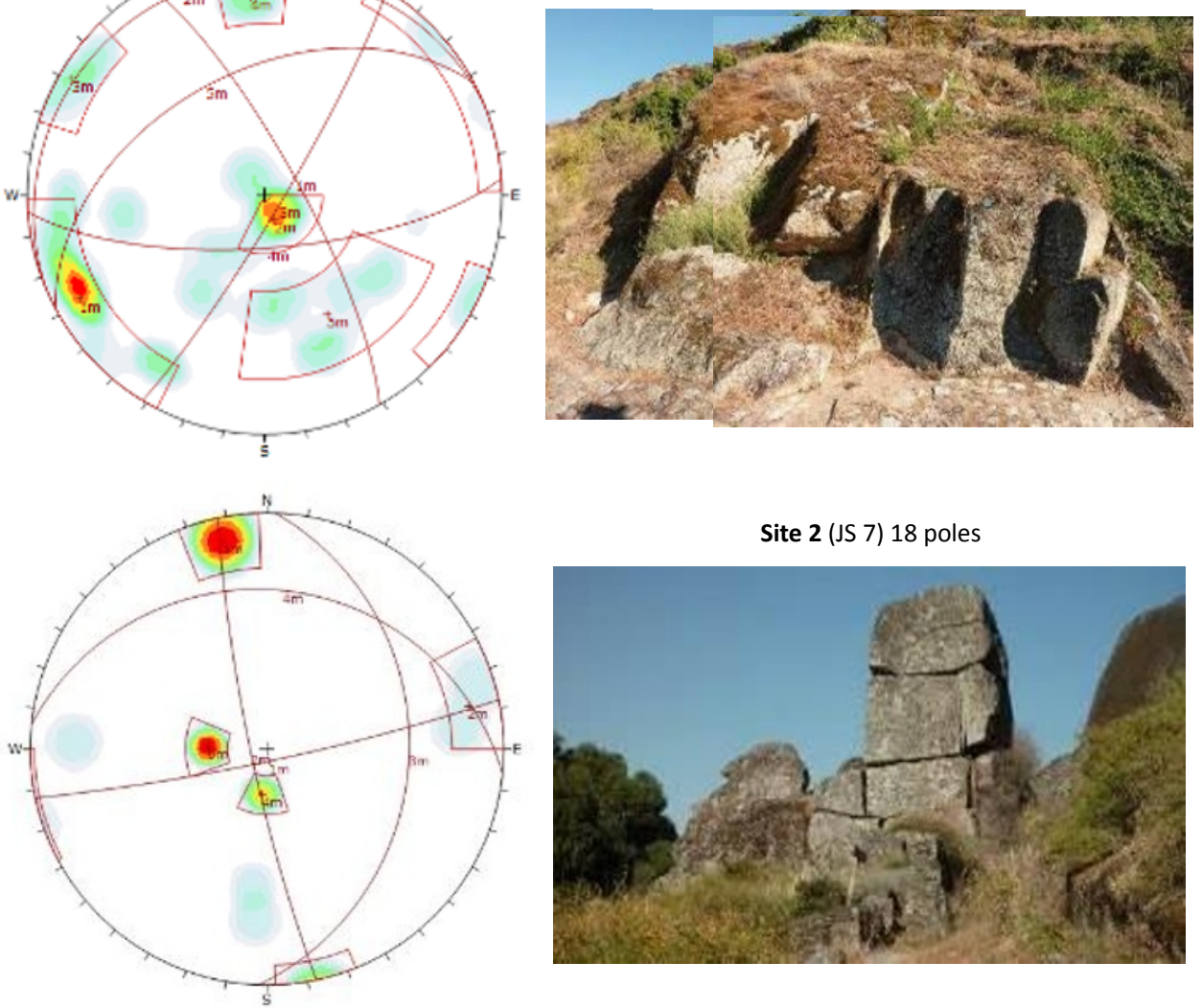

Site 2 (JS 7) 18 poles
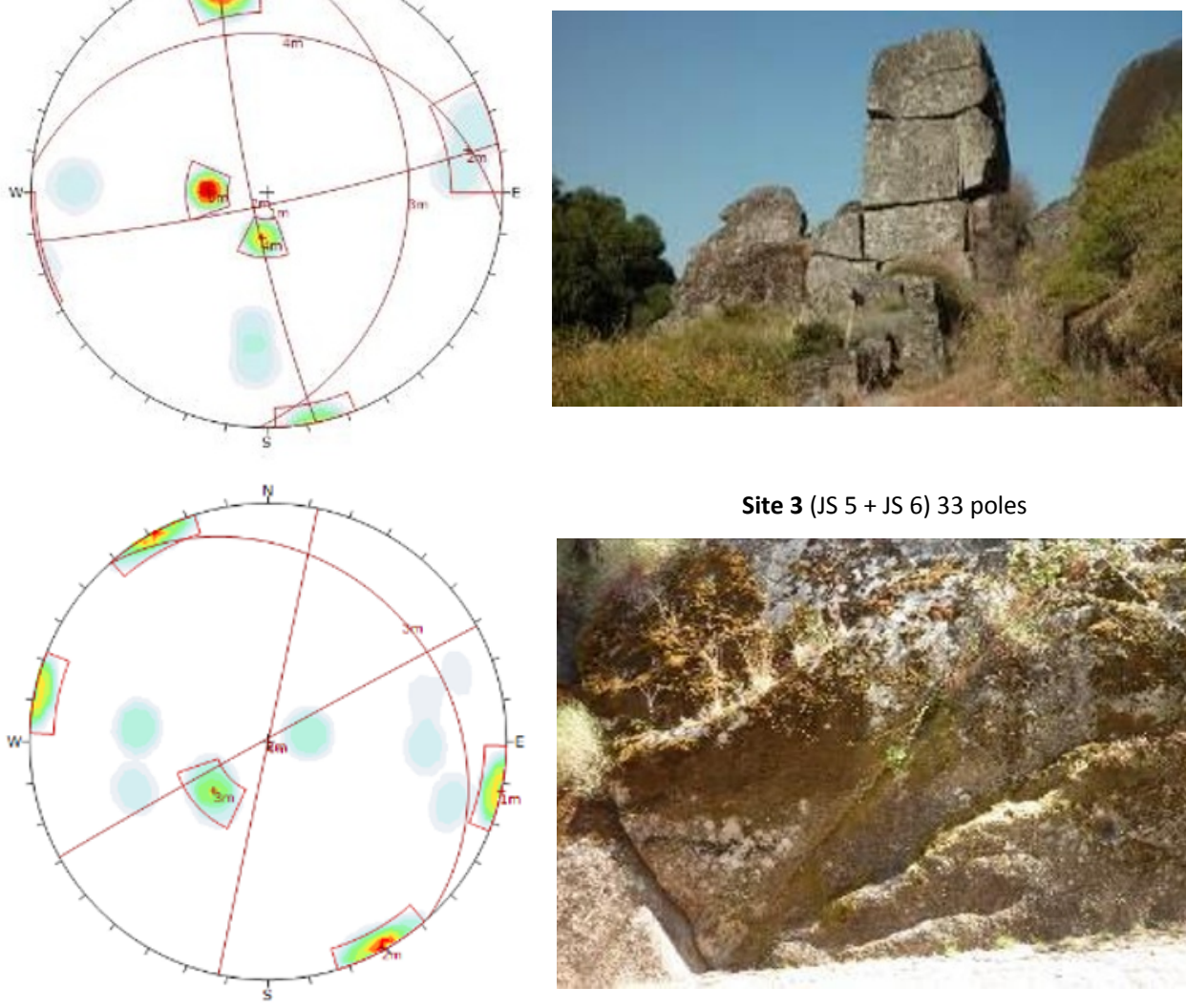

Site 3 (JS 5 + JS 6) 33 poles

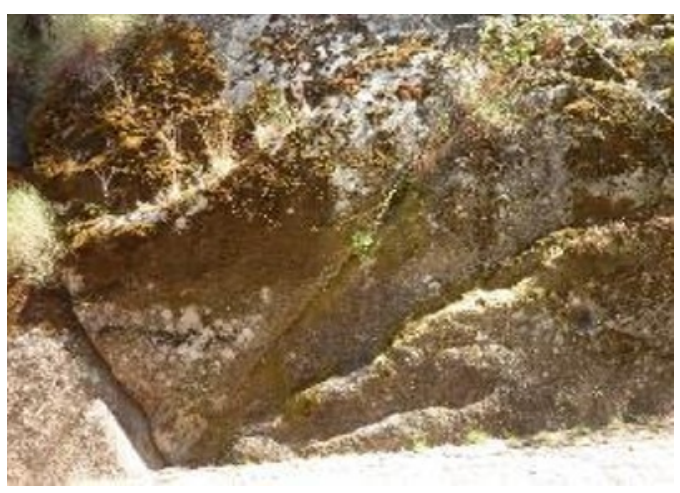

Fig. 4. Contour diagrams representing the orientation of the main sets of joints in Sites 1, 2 and 3 plotted on an equal-area net. (JS- joint station). 

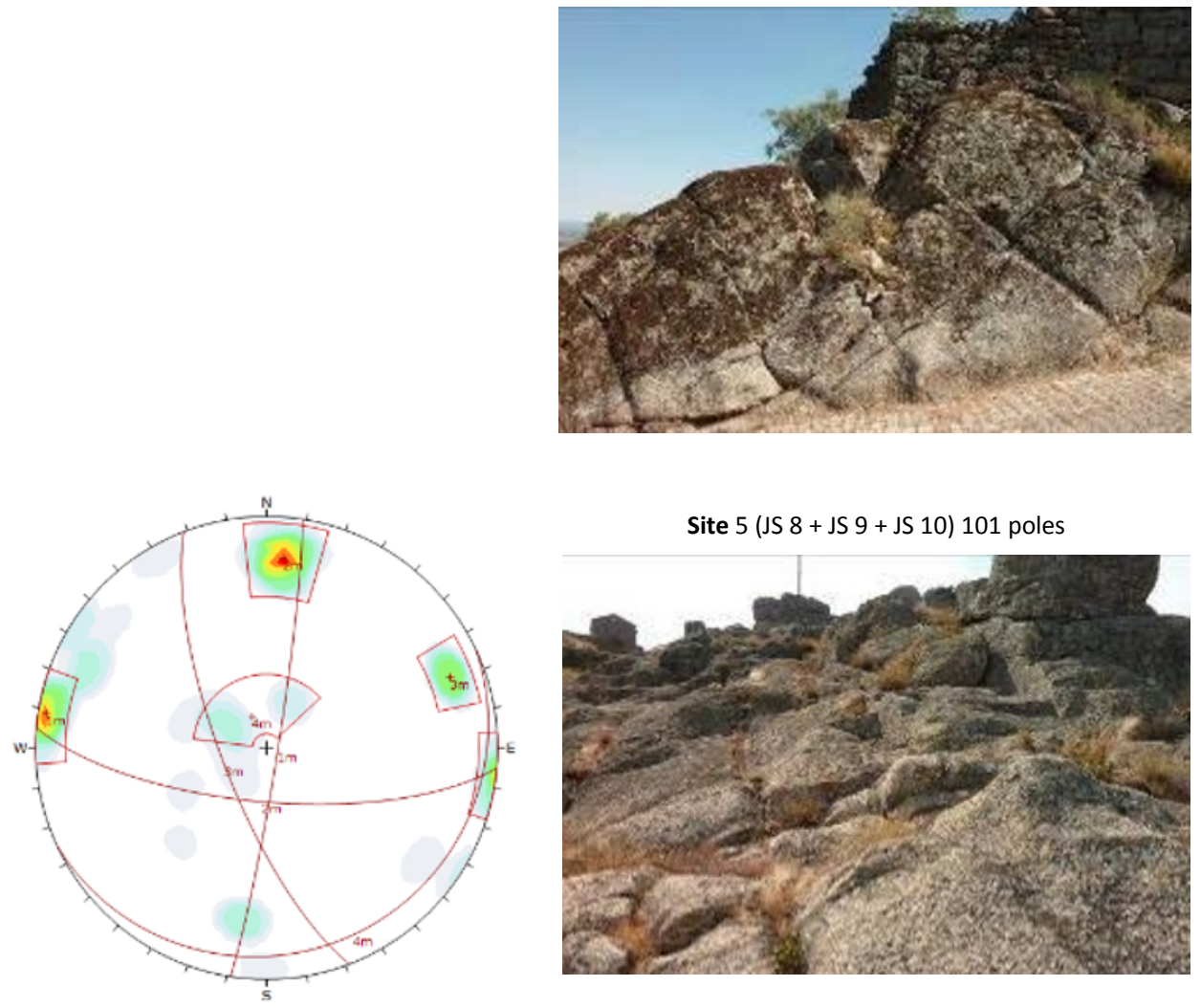

Fig. 5. Contour diagrams representing the orientation of the main sets of joints in Sites 3, 4 and 5 plotted on an equal-area net. (JS - joint station).

After the definition of the joint sets, histograms of the various parameters recorded during the field survey were built in order to determine the respective mean values. Table 1 shows a summary of those characteristics for each site and each joint set.

The spacing of the joints is predominantly F3 to F2 (moderate spacing to high spacing) and the joints show low $(1-3 \mathrm{~m})$ to medium $(3-10 \mathrm{~m})$ persistence. The lower values of persistence were registered in cut slopes of reduced height. The surfaces of the discontinuities show low to moderate roughness due to erosion, and this is also responsible for apertures of up to $100 \mathrm{~mm}$. The field survey was carried out during the dry season but the regular existence of brownish to black sediments suggest the occurrence of seepage through the joints. The joints were not found to have filling.

The Schmidt rebound obtained on the joint walls varied between 18 and 58, more frequently between 25 and 35. Using the correlation in [13], the Joint Wall Compressive Strength (JCS) was found to vary between 30 and $60 \mathrm{MPa}$. According to the classification proposed in [9], these values correspond to a medium hard to hard rock.

Table 1. Summary of the sets of joints and their characteristics.

\begin{tabular}{|c|c|c|c|c|c|}
\hline & Orientation & Spacing (F) & $\begin{array}{c}\text { Persistence } \\
(\mathbf{m})\end{array}$ & $\begin{array}{c}\text { Roughness } \\
(\mathbf{J R C})\end{array}$ & $\begin{array}{c}\text { Aperture } \\
(\mathbf{m m})\end{array}$ \\
\hline Site 1 & & & & & \\
Set 1 & $\mathrm{N} 151^{\circ} ; 78^{\circ} \mathrm{NE}$ & $\mathrm{F} 2$ & $1-3$ & $6-8$ & $.25-0.5$ \\
Set 2 & $\mathrm{N} 68^{\circ} ; 9^{\circ} \mathrm{NW}$ & $\mathrm{F} 2$ & $<1$ & $6-8$ & $<0,1$ \\
Set 3 & $\mathrm{N} 31^{\circ} ; 84^{\circ} \mathrm{SE}$ & $\mathrm{F} 3$ & $<1$ & $6-8$ & $0.25-0.5$ \\
Set 4 & $\mathrm{N} 86^{\circ} ; 72^{\circ} \mathrm{SSE}$ & $\mathrm{F} 2$ & $1-3$ & $6-8$ & $0.1-0.25$ \\
Set 5 & $\mathrm{N} 62^{\circ} ; 47^{\circ} \mathrm{NW}$ & $\mathrm{F} 2-3$ & $<1$ & $6-8 / 8-10$ & $0.25-0.5$ \\
\hline
\end{tabular}




\begin{tabular}{|c|c|c|c|c|c|}
\hline Site 2 & & & & & \\
Set 1 & $\mathrm{N} 78^{\circ} ; 84^{\circ} \mathrm{SSE}$ & $\mathrm{F} 2-3$ & $1-3 / 3-10$ & $6-8 / 10-12$ & $10-100$ \\
Set 2 & $\mathrm{N} 168^{\circ} ; 2^{\circ} \mathrm{WSW}$ & $\mathrm{F} 1-2$ & $3-10$ & $6-8 / 8-10$ & $10-100$ \\
Set 3 & $\mathrm{N} 2^{\circ} ; 28^{\circ} \mathrm{E}$ & $\mathrm{F} 3$ & $3-10$ & $6-8$ & $10-100$ \\
Set 4 & $\mathrm{N} 96^{\circ} ; 22^{\circ} \mathrm{NNE}$ & $\mathrm{F} 3$ & $1-3$ & $8-10$ & $0.25-0.5$ \\
\hline Site 3 & & & & & \\
Set 1 & $\mathrm{N} 12^{\circ} ; 90^{\circ}$ & $\mathrm{F} 3$ & $1-3$ & $4-6$ & $0.25-0.5$ \\
Set 2 & $\mathrm{N} 61^{\circ} ; 89^{\circ} \mathrm{NW}$ & $\mathrm{F} 3$ & $3-10$ & $6-8$ & $0.25-0.5$ \\
Set 3 & $\mathrm{N} 138^{\circ} ; 25^{\circ} \mathrm{NE}$ & $\mathrm{F} 2$ & $1-3$ & $6-8$ & $>1000$ \\
\hline Site 4 & & & & & \\
Set 1 & $\mathrm{N} 154^{\circ} ; 86^{\circ} \mathrm{NE}$ & $\mathrm{F} 3$ & $1-3$ & $4-6$ & $2.5-10$ \\
Set 2 & $\mathrm{N} 48^{\circ} ; 19^{\circ} \mathrm{NW}$ & $\mathrm{F} 3$ & $1-3$ & $4-6$ & $10-100$ \\
Set 3 & $\mathrm{N} 10^{\circ} ; 43^{\circ} \mathrm{ESE}$ & $\mathrm{F} 2$ & $1-3$ & $10-12$ & $10-100$ \\
\hline Site 5 & & & & & \\
Set 1 & $\mathrm{N} 9^{\circ} ; 86^{\circ} \mathrm{ESE}$ & $\mathrm{F} 2-3$ & $1-3$ & $8-10$ & $2.5-10$ \\
Set 2 & $\mathrm{N} 95^{\circ} ; 71^{\circ} \mathrm{SSW}$ & $\mathrm{F} 3$ & $>20$ & $4-6$ & $0.1-0.25$ \\
Set 3 & $\mathrm{N} 159^{\circ} ; 74^{\circ} \mathrm{SW}$ & $\mathrm{F} 3$ & $1-3$ & $10-12$ & $<0.1$ \\
Set 4 & $\mathrm{N} 65^{\circ} ; 12^{\circ} \mathrm{SE}$ & $\mathrm{F} 2$ & $3-10$ & $10-12$ & $2.5-10$ \\
\hline
\end{tabular}

\subsection{Laboratory testing}

The laboratory testing programme included the determination of the ultrasound propagation velocity and the uniaxial compressive strength on four samples. The measured ultrasonic propagation velocity varied between $2554 \mathrm{~m} / \mathrm{s}$ and $3357 \mathrm{~m} / \mathrm{s}$, with an average of $2879 \mathrm{~m} / \mathrm{s}$.

Subsequently, on the same set of samples, it was determined the uniaxial compressive strength under a constant loading rate of $1.8 \mathrm{KN} / \mathrm{s}$. Values of measured uniaxial compressive strength varied between 44.0 MPa and 55.4 MPa, with an average value of 49.9 MPa. These values fall within the range of uniaxial compressive strength values estimated from the rebound of the Schmidt hammer on weathered (W3) joints, using the correlation proposed in [13].

The scatter in the measurements may be due to the presence of mineral crystals of large dimensions in some samples, namely feldspar megacystals, or due to geometric imperfections in the samples, in particular close to the base and the top.

Comparison of the values measured in the laboratory tests described above with reference values for similar materials reported in the literature $[16,17]$ confirms the visual in-situ characterization that the granite rock mass is weathered (W3, locally W4) as a result of hydrothermal action and weathering.

\subsection{Shear strength of the discontinuities}

The angle of shearing resistance of the joints was estimated based on Equation 1, proposed in [11]:

$$
\tau=\sigma^{\prime} \cdot \operatorname{tg}\left[\mathrm{JRC} \cdot \log \left(\mathrm{JCS} / \sigma^{\prime}{ }_{\mathrm{n}}\right)+\phi_{\mathrm{r}}\right]
$$

where $\sigma_{n}^{\prime}$ is the normal effective stress, $\tau$ is the available shearing resistance, $\phi_{r}$ is the residual friction angle, that depends on the nature of the rock mass and degree of alteration of the joint, JRC is the Joint Roughness Coefficient and JCS is the Joint Wall Compressive Strength.

The residual friction angle, $\phi_{r}$ was estimated based on Equation 2 [11].

$$
\phi_{\mathrm{r}}=\left(\phi_{\mathrm{b}}-20\right)+20(\mathrm{r} / \mathrm{R})
$$

where $\phi_{b}$ is the basic friction angle measure on dry unweathered sawn surfaces, that for coarse grained granite varies between $31^{\circ}$ and $35^{\circ}$; $\mathrm{R}$ is the Schmidt rebound for dry 
unweathered sawn surfaces, that is estimated to be around 50 for coarse grained granite and $\mathrm{r}$ is the Schmidt rebound of the joints in-situ. For medium weathered joints, the average Schmidt rebound measured in the field was about 32, which corresponds to a uniaxial compressive strength of around $50 \mathrm{MPa}$. Based on the values above and assuming a value of $\phi_{b}$ equal to $31^{\circ}$ it is obtained a value of $\phi_{r}$ equal to $24^{\circ}$.

Assuming JCS equal to 6 and JRC equal to $50 \mathrm{MPa}$, for normal effective stresses in the range of 1 to $2 \mathrm{MPa}$ (based on the average block dimension and noting that the contact area is often very reduced) the angle of shearing resistance of the joints is expected to vary between $32^{\circ}$ and $34^{\circ}$. When the walls of the joints are strongly weathered, the value of the angle of shearing resistance is expected to be lower than that.

\section{Kinematic analysis}

Given the variability of conditions occurring at the 5 sites, the kinematic analysis was performed separately for the five sites and assuming the most conservative scenario, namely $60^{\circ}$ for the West slope angle and $45^{\circ}$ for the East slope angle. Based on the discussion above the angle of shearing resistance of the joints was assumed equal to $30^{\circ}$. The orientation of the slope at each site are as follows:

- Sites 1 and 2: $\mathrm{N} 90^{\circ} ; 60^{\circ} \mathrm{N}$

- Site 3: $\mathrm{N} 90^{\circ} ; 60^{\circ} \mathrm{N}$ (generic orientation) and $\mathrm{N} 15^{\circ} ; 60^{\circ} \mathrm{ESE}$ (at the scale of the outcrop)

- Site 4: $15^{\circ} ; 60^{\circ} \mathrm{ESE}$

- Site 5: $\mathrm{N}^{\circ} ; 45^{\circ} \mathrm{ESE}$ and $\mathrm{N} 35^{\circ} ; 45^{\circ} \mathrm{ESE}$

Table 2 presents the summary of the results obtained by the kinematic analysis. The movement that shows the highest probability of occurrence is direct toppling, with $100 \%$ probability at all sites. Direct toppling is found to occur along joints with dip angle varying between $9^{\circ}$ and $22^{\circ}$, except for Site 4 where it occurs associated with joints with dip angle of $43^{\circ}$. The probability of direct toppling decreases to $63 \%$ at site 5 when considering the orientation of $\mathrm{N}^{\circ}$. Flexural toppling has high probability of occurrence at Sites 1 and 2. Both sites are situated in the most problematic slope given that at his basis is located the school and the main access road to the village. Planar sliding can occur at Site 4 along joints dipping $43^{\circ} \mathrm{ESE}$. Site 4 corresponds to a cut of small extension and height where the blocks are still in situ, but the associated risk may still be significant. Wedge sliding shows the lowest probability of occurrence for all the sites.

Table 2. Results of the kinematic analysis. Probability of occurrence and associated joint set.

\begin{tabular}{|c|c|c|c|c|}
\hline 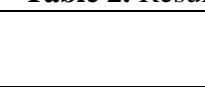 & Planar sliding & Wedge sliding & $\begin{array}{l}\text { Flexural } \\
\text { toppling }\end{array}$ & Direct toppling \\
\hline $\begin{array}{c}\text { Site 1 } \\
\text { JS 1+2 }\end{array}$ & $\begin{array}{c}36 \% \\
\mathrm{~N} 62^{\circ} ; 47^{\circ} \mathrm{NW} \\
\end{array}$ & 25 & $\begin{array}{c}100 \% \\
\mathrm{~N} 86^{\circ} ; 72^{\circ} \mathrm{SSE}\end{array}$ & $\begin{array}{c}100 \% \\
\mathrm{~N} 68^{\circ} ; 9^{\circ} \mathrm{NW}\end{array}$ \\
\hline $\begin{array}{c}\text { Site } 2 \\
\text { JS } 7\end{array}$ & 0 & 3 & $\begin{array}{c}100 \% \\
\text { N7 } 8^{\circ} ; 84^{\circ} \mathrm{SE} \\
\end{array}$ & $\begin{array}{c}100 \% \\
\text { N96 } ; 22^{\circ} \mathrm{NNE} \\
\end{array}$ \\
\hline $\begin{array}{c}\text { Site 3 } \\
\text { JS 5+6 }(\mathrm{N15}) \\
\end{array}$ & 15 & 12 & 6 & $\begin{array}{c}100 \% \\
\mathrm{~N} 138^{\circ} ; 25^{\circ} \mathrm{NE} \\
\end{array}$ \\
\hline $\begin{array}{c}\text { Site 3 } \\
\text { JS 5+6 }\left(\mathrm{N90}^{\circ}\right) \\
\end{array}$ & 0 & 6 & 0 & $\begin{array}{c}100 \% \\
\mathrm{~N} 138^{\circ} ; 25^{\circ} \mathrm{NE} \\
\end{array}$ \\
\hline $\begin{array}{c}\text { Site 4 } \\
\text { JS 3+4 }\end{array}$ & $\begin{array}{c}100 \% \\
\mathrm{~N} 10^{\circ} ; 43^{\circ} \mathrm{ESE}\end{array}$ & 16 & 3 & $\begin{array}{c}100 \% \\
\mathrm{~N} 10^{\circ} ; 43^{\circ} \mathrm{ESE}\end{array}$ \\
\hline $\begin{array}{c}\text { Site } 5\left(\mathrm{N6}^{\circ}\right) \\
\text { JS 8+9+10 }\end{array}$ & 4 & 3 & $\begin{array}{c}27 \% \\
\text { N9 } 9^{\circ} ; 86^{\circ} \mathrm{ESE}\end{array}$ & $\begin{array}{c}63 \% \\
\mathrm{~N} 65^{\circ} ; 12^{\circ} \mathrm{SE} \\
\end{array}$ \\
\hline $\begin{array}{c}\text { Site } 5\left(\mathrm{N35}^{\circ}\right) \\
\text { JS 8+9+10 }\end{array}$ & 2 & 2 & 0 & $\begin{array}{c}100 \% \\
\mathrm{~N} 65^{\circ} ; 12^{\circ} \mathrm{SE}\end{array}$ \\
\hline
\end{tabular}




\section{Conclusions}

The work presented in this paper is part of a wider project that aims to evaluate the risk associated with mass movements in an historic village in the centre of Portugal. This paper present some preliminary results namely the geologic-geotechnical characterization of the intervention area and the results of a kinematic analysis.

The granite rock mass was characterized both in what concerns the degree of weathering and fracturing, and the properties of the joint sets. The joint system originated rock boulders of large dimensions, some of which have been subjected to ancient movements, having rolled or fallen from higher elevation and now accumulate in irregular landforms. The blocks are prismatic to sub-rounded due to weathering along the joints $\left(\mathrm{W}_{4}\right.$ to $\mathrm{W}_{5}$ ). The joints are divided mainly in two subvertical sets and one sub-horizontal, which dips out of the slope.

The study of the rock mass was based on the collation of data at ten survey location (i.e. joint stations) regarding the properties of the joint system, namely orientation, spacing, persistence, aperture and roughness. The orientation of the predominant joint sets at each location were obtained by plotting the poles of the joints on an equal area net. These plots further enabled the kinematic analysis of each area.

Kinematic analyses were performed for five sites, which were obtained by grouping the joint stations according to the similarities in the occurring predominant joint sets. These five sites are considered representative of the geotechnical conditions occurring in the intervention area. The kinematic analysis assumed worst scenario conditions in what concerns the available shearing resistance of the discontinuities $\left(30^{\circ}\right)$ and the slope angles. The assumption of a low friction angle is justified by the fact that several blocks have very small contact areas with the rock mass on which they rest, due to severe weathering.

The kinematic analysis reveals a high probability of mass movements by direct toppling at all the sites considered. In what concerns the risk associated to mass movements, the slope above the school and the main access road to the village is the most problematic. On some of the sites there is also the possibility of flexural toppling to occur. Planar sliding can occur on Site 4 although this correspond to man-made slopes of limited height and extension.

The authors would like to acknowledge the institutions Naturtejo and Câmara Municipal de Idanha-aNova for their support in the development of the work presented in this paper. This work was carried out as part of the activities of Instituto Dom Luiz and the Publication is supported by FCT- project UID/GEO/50019/2019 - Instituto Dom Luiz.

\section{References}

1. L.K.A. Dorren, Prog. Phys. Geog., 27(1), 69-87 (2003)

2. C. Jaedicke, M. Van Den Eeckhaut, F. Nadim, J. Hervás, B. Kalsnes, B.V. Vangelsten, Bull Eng Geol Environ, 73(2), 325-339 (2014)

3. P. Gupta, R Anbalagan, Q J Eng Geol, 30, 27-36 (1997)

4. H.R. Pourghasemi, A.G. Jirandeh, B. Pradhan, C. Xu, C. Gokceoglu, J. Earth Syst. Sci., 122(2), 349-369 (2013)

5. A. Braathen, L.H. Blikra, S.S. Berg, F. Karlsen, Norw. J. Geol, 84(1) (2004)

6. L.R. Alejano, C. Ordóñez, J. Armesto, T. Rivas, Nat. Hazards, 53, 77-85 (2010)

7. J.A. Almeida, J.C. Kullberg, Nat. Hazards, 58(1), 289-310 (2011)

8. F. Guzzetti, M. Cardinali, P. Reichenbach, A. Carrara, Environ Manage, 25(3), 247-263 (2000)

9. ISRM, Int. J. Rock Mech. Min. Sci., 15, 319-368 (1979a) 
10. M. Ferrer, L.G. Vallejo, Manual de campo para la descripción y caracterización de macizos rochosos en afloramentos (2007)

11. N. Barton, V. Choubey, Rock Mech., 10 (1-2), 1-54 (1977)

12. ISRM, Int. J. Rock Mech. Min. Sci., 15, 89-9 (1978a)

13. D.U. Deere, R.P. Miller, Technical Report $N^{o} A F W L-T R-65-116$, Uni. of Illinois (1966)

14. ISRM, Int. J. Rock Mech. Min. Sci., 15, 53-58 (1978b)

15. ISRM, Int. J. Rock Mech. Min. Sci., 16, 135-140 (1979b)

16. L.G. Vallejo, M. Ferrer, L. Ortuño, C. Oteo, Ingenieria Geologica (2002)

17. M. Rocha, Introdução à Mecânica das Rochas (2013) 